\title{
Internationaal procederen
}

\section{Verslag van de voorjaarsvergadering 2015 van de Nederlandse Vereniging voor Procesrecht}

\author{
Mr.J.J. Dammingh en mr. L.M. van den Berg*
}

\begin{abstract}
Algemeen
De voorjaarsvergadering van 2015 van de Nederlandse Vereniging voor Procesrecht (hierna: NVvP) had als onderwerp 'Internationaal procederen'. De voorzitter, prof. mr. C.J.M. Klaassen, merkte in haar inleiding hierover het volgende op. In de praktijk zijn er veel geschillen met een 'internationale component'. Denk bijvoorbeeld aan een in Nederland gevestigd bedrijf dat een handelsgeschil heeft met een buitenlandse onderneming. Internationaal opererende ondernemingen hebben behoefte aan een gerecht dat dergelijke (internationale) handelsgeschillen deskundig en efficiënt kan beslechten. Vandaar dat ook de Raad voor de rechtspraak nadenkt over de oprichting (in Nederland) van een 'commercial court': een speciale rechtbank die internationale handelsgeschillen binnen een paar maanden kan afdoen via een efficiënte en Engelstalige procedure (met harde deadlines).

Naast voornoemde handelsgeschillen zijn er vele andere geschillen met een internationale component. Gewezen kan bijvoorbeeld worden op (internationale) echtscheidingen, arbeidsgeschillen, de aankoop van een (tweede) huis in het buitenland en letselschadezaken vanwege ondeugdelijke implantaten.
\end{abstract}

In geval van internationaal procederen rijzen tal van vragen, zoals: welke rechter is bevoegd, hoe en waar kan er conservatoir beslag worden gelegd, welk recht is van toepassing, op welke wijze kan bewijs worden geleverd, hoe en waar kan een rechterlijke uitspraak (in de hoofdzaak) ten uitvoer worden gelegd? Deze vergadering concentreert zich op twee aspecten: ten eerste de feiten- en bewijsvergaring in internationale procedures, en ten tweede zekerheidstelling. Ten aanzien van de feitenvergaring zal met name aandacht worden gevraagd voor 'disclosure' c.q. 'discovery', en in het kader van zekerheidstelling wordt onder meer het EU-bankbeslag besproken. Stellingen:

\section{Inleiding mr. drs. A.R.J. Croiset van Uchelen}

\footnotetext{
Mr. J.J. Dammingh is universitair hoofddocent burgerlijk (proces)rech aan de Radboud Universiteit Nijmegen. Mr. L.M. van den Berg is senior juridisch medewerker in de Rechtbank Gelderland en tevens verbonden aan de sectie burgerlijk (proces)recht van de Radboud Universiteit Nijmegen.
}

1. Wat de common law-jurisdicties te veel hebben aan disclosure/discovery, hebben wij (en de civil law-jurisdicties in het algemeen) te weinig.

2. De internationalisering van het rechtsverkeer moet tot convergentie tussen beide systemen leiden, met echter als blijvend verschil dat in de civil law-jurisdicties een (volwaardig) inhoudelijk debat in beginsel voorafgaat aan (uitgebreide) disclosure/discovery en daaraan moeten we ook willen vasthouden.

3. In Nederland leiden enquêteonderzoeken, WOB-verzoeken, terbeschikkingstelling van strafdossiers aan benadeelde partijen, discovery in het buitenland (zoals 28 USC 1782) en (openbare) maatregelen van toezichthouders de facto al tot een grote, maar onevenwichtige mate van (pretrial) discovery.

\section{Inleiding}

Croiset van Uchelen wijst erop dat in toenemende mate behoefte is ontstaan - vooral bij grote, internationaal opererende ondernemingen - aan international commercial courts'. Hiermee worden gerechten bedoeld die in staat zijn om internationale handelsgeschillen te beslechten en daartoe ook bevoegd zijn zonder dat er aanknopingspunten hoeven te zijn met het land waar het geschil speelt c.q. de plaats waar partijen hun domicilie hebben. In meerdere landen zijn al dergelijke gerechten (hierna: commercial courts) gevestigd.

De Raad voor de rechtspraak wil zich sterk maken voor de oprichting van een commercial court in Nederland. In zijn toespraak op de Dag van de Rechtspraak van 2014 heeft de voorzitter van de Raad voor de rechtspraak, Frits Bakker, hierover opgemerkt:

'Ook voor een sterke extern georiënteerde handelseconomie heeft Nederland een sterke rechtspraak nodig. Die geschillen snel en deskundig oplost. Een rechtspraak die voor bedrijven reden is hun handelsgeschillen in Nederland af te wikkelen - in plaats van in Londen of Singapore. Als we dat willen, dames en heren, moeten we vandaag actie ondernemen. Onze rechters hebben veel expertise in huis. Multinationals als Gazprom, Apple en Gucci laten Nederlandse rechters al regelmatig hun oordeel geven. Maar er is meer nodig, als we economisch en juridisch aan 
de top willen blijven. Daarom gaat de Raad voor de Rechtspraak zich inzetten voor de oprichting van een commercial court: een speciale rechtbank die grote internationale en nationale handelsgeschillen binnen een paar maanden kan afdoen. Met efficiënte, Engelstalige procedures. Harde deadlines.

Nederlandse rechters horen bij de top-vijf in de wereld. Zijn bijzonder deskundig in grote handelsgeschillen. Met sterke specialisaties zoals intellectueel eigendom, vervoersrecht en ondernemingsrecht. Rechters die de wereldhandel en de haven hier in Rotterdam als hun broekzak kennen. Hun specialiteit komt in een commercial court helemaal tot zijn recht. Natuurlijk kan de rechtspraak dit niet alleen. Wij zullen een beroep doen op de regering en de politiek, maar ook op het bedrijfsleven en de advocatuur om de oprichting van een commercial court voluit te steunen. Een centrum met hoogwaardige juridische infrastructuur helpt mee aan een sterke economie en meer banen.' ${ }^{1}$

Wat beweegt (commerciële) partijen die een handelsgeschil willen laten beslechten ertoe om voor het ene of het andere commercial court te kiezen? Volgens Croiset van Uchelen leert de ervaring dat aspecten als de integriteit van de rechter, de kosten van de procedure, de voortgang, de duur en de 'organisatie' van de procedure alsmede de mogelijkheid van een proceskostenveroordeling gewicht in de schaal leggen in dit verband. De kosten van een procedure bij een commercial court in het Verenigd Koninkrijk blijken erg hoog te zijn. Er liggen dus zeker kansen voor een commercial court in ons land, ook omdat Nederland politiek gezien als 'neutraler' heeft te gelden.

Echter: een belangrijk - zo niet het belangrijkste - aspect bij de keuze voor het ene dan wel het andere commercial court blijkt te zijn de mate waarin disclosure/discovery kan plaatsvinden, en op dat punt scoort Nederland internationaal gezien niet zo goed, aldus Croiset van Uchelen. Met 'disclosure' c.q. 'discovery' wordt gedoeld op de mogelijkheid voor een partij om af te dwingen dat (digitale) documenten die zich onder de wederpartij of een derde bevinden en die relevant zijn voor de beoordeling van een geschil, aan de rechter (en de verzoekende partij) worden overgelegd. In Nederland spreekt men in dit verband van het 'inzagerecht' of de 'exhibitieplicht'. In 'common law'-landen als de Verenigde Staten en het Verenigd Koninkrijk geldt een (zeer) ruime mate van disclosure/discovery. In 'civil law'-landen zijn de mogelijkheden om inzage in bescheiden te verkrijgen echter aanmerkelijk minder ruim. (NB Zie ook de eerste stelling van Croiset van Uchelen.)

In ons Wetboek van Burgerlijke Rechtsvordering ( $\mathrm{Rv})$ is het inzagerecht geregeld in art. 843a. Het betreft een - in internationaal perspectief - 'magere' regeling, waarmee volgens Croi-

1. De volledige tekst van de toespraak is te vinden op <www.rechtspraak. $\mathrm{nl}>$. Zie hierover ook o.m. M. Ynzonides \& M. de Boer, Kroniek van het burgerlijk procesrecht, NJB 2014/1829, p. 2457-2467 en C.J.M. Klaassen, Kroniek van de civiele rechtspleging, NJB 2015/738, p. 1027-1042. set van Uchelen in de praktijk onvoldoende effect wordt gesorteerd. Zowel Ekelmans (advocaat) als Sijmonsma (rechter) heeft een dissertatie over de regeling van art. 843a Rv geschreven. $^{2}$ Het artikel bepaalt (in lid 1) dat hij die daarbij rechtmatig belang heeft, inzage kan vorderen in bescheiden aangaande een rechtsbetrekking (waarbij hij partij is) van degene die deze bescheiden onder zich heeft. Het inzagerecht staat in het teken van het bewijsrecht: met het oog op door haar te leveren bewijs moet een partij aanspraak kunnen maken op inzage in c.q. afgifte van bescheiden waarvan het bestaan haar bekend is, maar waarover zij niet beschikt. Art. 843a Rv biedt hiertoe de mogelijkheid: indien aan de in het artikel genoemde eisen is voldaan, kan de overlegging van bescheiden worden afgedwongen. Degene tegen wie een dergelijke vordering (in rechte) is ingesteld, hoeft evenwel geen inzage te verlenen indien redelijkerwijs kan worden aangenomen dat een behoorlijke rechtsbedeling ook zonder de gevorderde inzage is gewaarborgd. Deze 'subsidiariteit' ligt in art. 843a lid $4 \mathrm{Rv}$ besloten: inzage kan achterwege blijven indien het bewijs op andere wijze (bijvoorbeeld door middel van getuigen) kan worden geleverd.

Bij de Tweede Kamer ligt, sinds medio 2011, wetsvoorstel 33079, strekkend tot aanpassing van de wettelijke regeling van het inzagerecht. Volgens dit wetsvoorstel is het onder meer de bedoeling om het inzagerecht te verplaatsen van het derde boek Rv naar de afdeling over het bewijsrecht in het eerste boek. Verder is in het wetsvoorstel, waarvan onduidelijk is of en wanneer het wet zal worden, de 'subsidiariteit' niet meer terug te vinden. ${ }^{3}$

De Nederlandse rechtspraak over een vordering tot inzage op de voet van art. 843a $\mathrm{Rv}$ is volgens Croiset van Uchelen zeer onvoorspelbaar. Het gebeurt meer dan eens dat een vordering wordt afgewezen omdat deze naar het oordeel van de rechter in een te vroegtijdig stadium (van de procedure) is ingesteld of te ruim is geformuleerd (waardoor sprake zou zijn van een 'fishing expedition'). Ook wordt een inzagevordering nogal eens afgewezen omdat de vereiste 'rechtsbetrekking' ontbreekt. ${ }^{4} \mathrm{De}$ timing blijkt volgens Croiset van Uchelen cruciaal te zijn: vaak acht de rechter het wenselijk dat eerst het processuele debat wordt afgegrensd voordat over exhibitie kan worden gesproken. Het lijkt Croiset van Uchelen een goede suggestie om in het comparitievonnis (ook) te vermelden dat partijen bij de comparitie kunnen aangeven welke bescheiden volgens hen (nog) in het geding gebracht behoren te worden. Ten aanzien van de omvang van een inzagevordering is hij van mening dat een exhibitie best ruim mag zijn nadat een bewijsopdracht is verstrekt.

2. J. Ekelmans, De exhibitieplicht (diss. Groningen), Deventer: Kluwer 2010 en J.R. Sijmonsma, Het inzagerecht. Artikel 843a van het Wetboek van Burgerlijke Rechtsvordering (diss. Maastricht), Deventer: Kluwer 2010. Zie over deze proefschriften o.m. J.J. Dammingh, Boekbespreking, RMThemis 2013, afl. 1, p. 36-44.

3. Kamerstukken II 2011/12, 33079, 2 (voorstel van wet)

4. Zie over het vereiste van een 'rechtsbetrekking' o.m. HR 10 juli 2015, ECLI:NL:HR:2015:1834, RvdW 2015/861 (Eiser c.s./Staat). 
Hoe dan ook: een veelgehoord bezwaar tegen commercial courts in de civil law-jurisdicties is dat de toepassingsmogelijkheden van disclosure/discovery onvoldoende (ruim) zijn. Dat zou dus tegen een in Nederland gevestigd commercial court (kunnen) pleiten. Croiset van Uchelen acht convergentie op dit punt tussen common law-jurisdicties en civil law-jurisdicties aangewezen, zij het dat in de civil law-jurisdicties een (volwaardig) inhoudelijk debat in beginsel vooraf moet blijven gaan aan een (uitgebreide) disclosure/discovery. (NB Zie de tweede stelling van Croiset van Uchelen.) Exhibitie in een later stadium van de procedure is namelijk efficiënter en minder kostbaar (dan voorafgaand aan het processuele debat).

Croiset van Uchelen wijst er voorts op dat bij de discussie over de - wenselijk te achten - mate van 'discovery' in Nederland ook in aanmerking moet worden genomen dat toezichthouders als DNB, AFM en ACM vergaande (wettelijke) bevoegdheden hebben tot het vorderen van inzage in documenten. Ook parlementaire enquêtes en WOB-verzoeken leiden de facto al tot een ruime - maar onevenwichtige - mate van (pretrial) discovery, en hetzelfde geldt voor het ter beschikking stellen van strafdossiers aan benadeelde partijen. (NB Zie de derde stelling van Croiset van Uchelen.)

Als we toch al deze vergaande mogelijkheden tot discovery kennen, waarom zou dan niet ook de (Nederlandse) rechter wat ruimhartiger met een inzageverzoek kunnen c.q. moeten omgaan? Met deze vraag (c.q. opmerking) besluit Croiset van Uchelen zijn betoog.

\section{Discussie}

De heer Punt (oud-rechter) merkt op dat de historische achtergrond van de discovery-praktijk in de common law-jurisdicties is gelegen in de juryrechtspraak. Hij vraagt zich af of er een wettelijke basis nodig zal zijn voor een commercial court in Nederland.

Croiset van Uchelen denkt dat een wetswijziging wellicht nodig is voor het (kunnen) procederen in de Engelse taal. Voor het overige zal zo'n commercial court volgens hem binnen de grenzen van de bestaande (procesrechtelijke) wetgeving kunnen functioneren.

De heer Gerretsen (advocaat) vraagt zich af in hoeverre procederen bij een (eventueel) in Nederland op te richten commercial court zich zal onderscheiden van (internationale) arbitrage.

In zijn reactie wijst Croiset van Uchelen erop dat het verschil onder meer in de rechtsvorming zal zijn gelegen. Arbitrage is niet openbaar en de rechtspraak van een commercial court wel. Met zijn jurisprudentie zou zo'n commercial court zich 'in de markt' kunnen zetten.

De heer Wehrmeijer (advocaat) stelt dat de 'lat' bij een voorlopig getuigenverhoor aanmerkelijk lager ligt dan bij een inzagevordering op de voet van art. 843a Rv.

Croiset van Uchelen onderschrijft deze stelling; wat hem betreft gaat de 'lat' bij een voorlopig getuigenverhoor enigszins omhoog en bij een inzagevordering omlaag (zodat het 'gelijk wordt getrokken').

Mevrouw Van Hoek (hoogleraar aan de UvA) vraagt zich af welke rol het materiële recht speelt bij de keuze voor een in een common law- dan wel in een civil law-land gevestigd commercial court.

Volgens Croiset van Uchelen spelen de materieelrechtelijke verschillen tussen enerzijds de common law-jurisdicties en anderzijds de civil law-jurisdicties zeker een rol, maar moeten deze niet worden overschat. Naar zijn mening worden de verschillen in materieelrechtelijk opzicht nogal eens overdreven.

\section{Inleiding mw. mr. S.M.C. Nuijten}

Stellingen:

1. Nederlandse toezichthouders mogen hun toezichtbevoegdheden niet buiten Nederland inzetten.

2. Alle (elektronische) informatie die vanuit Nederland kan worden ingezien, moet worden geacht zich in Nederland te bevinden, ongeacht de locatie van de betrokken server.

3. Nederlandse toezichthouders moeten buitenlandse toezichthouders kunnen verplichten tot invordering van bestuurlijke boetes over te gaan.

\section{Inleiding}

Nuijten gaat in op de mogelijkheden van toezichthouders als de AFM, de ACM en DNB om - bestuursrechtelijke - instrumenten internationaal in te zetten. Kan een toezichthouder bijvoorbeeld inzage verkrijgen in documenten die zich in het buitenland bevinden? Bij de inzet van instrumenten door een toezichthouder moet een onderscheid worden gemaakt tussen enerzijds toezicht en anderzijds handhaving.

Met betrekking tot 'toezicht' noemt Nuijten de volgende instrumenten:

\section{Inlichtingenvordering}

Door middel van een inlichtingenvordering kan een toezichthouder een ander verplichten om vragen te beantwoorden. Aan het niet naleven van de medewerkingsplicht die met zo'n vordering samenhangt, wordt in veel bijzondere wetten een last onder dwangsom of een bestuurlijke boete verbonden. Een inlichtingenvordering kan worden ingezet tegen personen die betrokken zijn bij activiteiten waarop het (wettelijke) toezicht wordt uitgeoefend.

2. Inzagevordering

Een toezichthouder kan inzage vorderen in zakelijke bescheiden (niet in persoonlijke). Deze bevoegdheid - die ook ziet op elektronische documenten - kan in ieder geval worden ingezet bij een bedrijfsbezoek.

3. De bevoegdheid plaatsen te betreden

Een toezichthouder is soms op grond van de wet bevoegd om plaatsen te betreden, waarbij hij zo nodig apparatuur mag meebrengen en/of zich door personen mag laten vergezellen. 
De inzet van deze toezichtinstrumenten wordt getoetst aan het evenredigheidsbeginsel: de toezichthouder mag van zijn bevoegdheden slechts gebruik maken voor zover dat voor de vervulling van zijn taak redelijkerwijs nodig is.

Maar de vraag die vandaag centraal staat, is of genoemde bevoegdheden internationaal mogen worden ingezet. In dit verband is het zogenoemde 'territorialiteitsbeginsel' relevant: een staat mag zijn bevoegdheden niet op het grondgebied van een andere staat uitoefenen, tenzij een verdrag of een bepaling in de andere staat een grondslag voor de uitoefening van die bevoegdheden biedt. Dit betekent dat als uitgangspunt geldt dat Nederlandse toezichthouders hun bevoegdheden niet buiten Nederland mogen inzetten. (NB Zie de eerste stelling van Nuijten.) In Europese richtlijnen besloten liggende samenwerkingsverplichtingen kunnen echter meebrengen dat bevoegdheden wel in een andere lidstaat mogen worden uitgeoefend. Nuijten wijst onder meer op de Wet toezicht accountantsorganisaties (Wta), die bepalingen bevat ter implementatie van (samenwerkingsverplichtingen uit) Richtlijn 2006/43/EG (aangaande de controle van jaarrekeningen). Als de AFM op verzoek van een buitenlandse toezichthouder onderzoek verricht, dan kan die buitenlandse toezichthouder verzoeken om daarbij aanwezig te mogen zijn, zo volgt bijvoorbeeld uit art. 63h Wta.

Nuijten benadrukt dat de toenemende internationalisering en digitalisering nogal wat problemen veroorzaken. Als voorbeeld noemt zij het verhuren van de eigen woning aan toeristen. Hiermee worden door de aanbieder (van de woning) diverse voorschriften overtreden. Dat aanbieden gebeurt vaak via een website. Mag de toezichthouder persoonsgegevens vorderen van de aanbieder van de website indien deze in het buitenland is gevestigd? Nuijten wijst in dit verband op haar tweede stelling: alle (elektronische) informatie die vanuit Nederland kan worden ingezien, moet geacht worden zich in Nederland te bevinden, ongeacht de locatie van de betrokken server. Er zijn goede argumenten voor, maar ook tegen deze stelling. Aan de ene kant past het niet meer bij deze tijd om een beslissende rol aan de locatie van de server toe te kennen. Daar staat echter tegenover dat het territorialiteitsbeginsel elke betekenis zou verliezen wanneer ervan uit wordt gegaan dat alle informatie die vanuit Nederland kan worden ingezien, zich in Nederland bevindt.

Ten aanzien van 'handhaving' kan de vraag worden opgeworpen of en hoe een sanctie kan worden opgelegd aan een buiten Nederland gevestigde (rechts)persoon. Nuijten merkt op dat toezichthouders daar in de praktijk nogal pragmatisch mee omgaan: ook aan buitenlandse partijen worden boetes opgelegd, maar er worden verder geen maatregelen genomen wanneer een boete niet wordt betaald. In Nederland kan een bestuurlijke boete bij dwangbevel (door een bestuursorgaan) worden ingevorderd. Een dwangbevel levert zonder tussenkomst van de rechter een executoriale titel in Nederland op. Zonder verdragsrechtelijke grondslag kan een bestuurlijke boete niet in een andere staat worden geïnd. In dit verband is van belang dat in Nederland bestuurlijke boetes door het bestuursorgaan - en dus niet door de rechter - worden opgelegd, waarna de oplegging vervolgens door de bestuursrechter kan worden getoetst. Er zijn lidstaten die de op deze wijze geboden rechtsbescherming onvoldoende vinden om de inning op hun grondgebied toe te staan. Het spreekt voor zich dat deze situatie onwenselijk is. Nuijten wijst op haar derde stelling: Nederlandse toezichthouders zouden buitenlandse toezichthouders moeten kunnen verplichten tot de invordering van bestuurlijke boetes over te gaan. Hier ligt volgens haar een kans voor de Europese wetgever: die kan - teneinde een dergelijke invordering mogelijk te maken - aan de procedure en de rechtsbescherming in de lidstaten minimumeisen stellen.

\section{Discussie}

Mevrouw Tzankova (advocaat en hoogleraar te Tilburg) vraagt wat de informele reikwijdte is van de door een toezichthouder uit te oefenen bevoegdheden. Kan een toezichthouder bijvoorbeeld informatie verkrijgen van een in het buitenland gevestigde dochtermaatschappij?

In haar antwoord stelt Nuijten dat die mogelijkheden er inderdaad zijn: de bevoegdheden worden in de praktijk meer dan eens 'opgerekt' en gebruikt voor een ander doel dan waarvoor zij zijn verleend.

Mevrouw Van Hoek (hoogleraar aan de UvA) vraagt zich af welke lidstaat de kosten van het innen van bestuurlijke boetes in een andere lidstaat draagt.

Nuijten erkent in haar reactie dat de kosten van inning een groot probleem vormen en vakk om die reden een invordering achterwege blijft.

\section{Inleiding mr. W.H.A.M. van den Muijsenbergh} Stellingen:

1. Aangezien op dit moment nog geen sprake is van een in alle landen van de Europese Unie goed functionerende, onpartijdige en onafhankelijke rechterlijke macht, is het risico dat het Europees bankbeslag tot misbruik leidt reëel en zal de Nederlandse rechter niet terughoudend moeten zijn om, indien een vermoeden van misbruik bestaat, een 'openbareordetoets' te doen.

2. De in Nederland als basisbeginsel gehanteerde regel dat een debiteur niet tot het stellen van zekerheid kan worden verplicht indien daarvoor geen contractuele grondslag bestaat, dient te worden herzien. In navolging van wat in de Verenigde Staten mogelijk is, dient ook de Nederlandse rechter een debiteur te kunnen verplichten tot het stellen van zekerheid op straffe van een sanctie vergelijkbaar met de Angelsaksische sanctie ter zake van 'contempt of court'.

\section{Inleiding}

Van den Muijsenbergh kondigt aan dat hij omwille van de tijd met name zijn eerste stelling zal bespreken. Hij zal het publiek niet belasten met een integrale bespreking van het EU-bank- 
beslag,' maar wel een paar kritische kanttekeningen bij de regeling plaatsen.

Verordening 655/2014 inzake het EU-bankbeslag (hierna: de Verordening) roept voor een schuldeiser de Unierechtelijke mogelijkheid in het leven om - met het oog op de inning van zijn vordering - een 'bevel tot conservatoir beslag' te verkrijgen ter zake van banktegoeden van een schuldenaar in andere landen van de EU. Het is op zichzelf een goede ontwikkeling dat dit bankbeslag er komt. Crediteuren krijgen hierdoor meer mogelijkheden tot (conservatoire) beslaglegging met het oog op de inning van hun vorderingen. Maar de Verordening brengt ook risico's mee, aldus Van den Muijsenbergh.

Zo schept art. 14 van de Verordening de mogelijkheid om het gerecht waaraan het bevel is gevraagd, tevens te verzoeken in de lidstaat van tenuitvoerlegging navraag te doen naar de bankgegevens van de schuldenaar in die lidstaat, zodat het beslag onder de juiste bank(en) kan worden gelegd. Dit vergroot uiteraard de effectiviteit van het beslag. Navraag moet worden gedaan bij een door de lidstaten in te stellen 'informatie-instantie'. Deze instantie zal toegang moeten krijgen tot overheidsgegevens. Bovendien zullen zowel de schuldenaar als de nationale banken gehouden zijn om aan deze instantie bankgegevens te verstrekken. Het betreft hier gevoelige informatie. Deze informatie kan ook worden ingewonnen als de crediteur nog niet over een executoriale titel beschikt. Het risico bestaat dus dat het bevel met een gefingeerde vordering wordt gevraagd ter verkrijging van deze gegevens. Het gerecht dat om het bevel is gevraagd, zal hier alert op moeten zijn.

Van den Muijsenbergh wijst verder op art. 22 van de Verordening. Daarin is bepaald dat een bevel tot conservatoir beslag in de andere lidstaten zonder meer wordt erkend en uitvoerbaar is. Dit is in lijn met de herschikte EEX-Verordening. ${ }^{6}$ Er vindt geen rechterlijke toetsing van een bevel plaats in de lidstaat van beslaglegging. Het komt dus aan op de beoordeling door de rechter die het bevel moet geven. Met name over rechters in Oost-Europese landen bestaan echter zorgen wat betreft hun onafhankelijkheid en onpartijdigheid. Uit informatie op de Business Anti-Corruption Portal ${ }^{7}$ blijkt dat de gerechten in sommige van die landen door grote delen van de bevolking niet worden vertrouwd en ook dat daar in variërende mate sprake is van daadwerkelijke corruptie in het judiciële systeem. Niet valt dus uit te sluiten dat rechters worden bewogen tot

5. Verordening (EU) 655/2014 van het Europees Parlement en de Raad van 15 mei 2014 tot vaststelling van een procedure betreffende het Europees bevel tot conservatoir beslag op bankrekeningen om de grensoverschrijdende inning van schuldvorderingen in burgerlijke en handelszaken te vergemakkelijken, PbEU 2014, L 189, 27 juni 2014, p. 59 e.v. Zie D.M. de Knijff, Kroniek Beslag- en executierecht, TCR 2015, afl. 3, p. 96 e.v., voor verdere literatuurverwijzingen. Zie ook J.M. Atema \& E.C. Netten, Het Europees bankbeslag: een ruwe diamant, MvV 2012, afl. 2, p. 11 e.v., waarin een conceptversie van de Verordening wordt besproken.

6. Verordening (EU) 1215/2012 van het Europees Parlement en de Raad van 12 december 2012 betreffende de rechterlijke bevoegdheid, de erkenning en de tenuitvoerlegging van beslissingen in burgerlijke en handelszaken (herschikking), PbEU 2012, L 351, 20 december 2012, p. 1 e.v.

7. Zie <www.business-anti-corruption.com>. afgifte van bevelen op oneigenlijke gronden. Er bestaat daardoor een reële mogelijkheid van ongefundeerde beslaglegging, ook onder Nederlandse banken, en ook ten laste van hier gevestigde grote internationale ondernemingen. Dergelijke beslagen kunnen aanzienlijke schade tot gevolg hebben. Deze schade zal in de regel niet te verhalen zijn. Volgens Van den Muijsenbergh is het daarom spijtig dat het bevel in het land van tenuitvoerlegging niet wordt getoetst, bijvoorbeeld aan de openbare orde. Het is nu de debiteur die steeds zelf in actie moet komen, in de eerste plaats door het bevel in het buitenland aan te vechten.

\section{Discussie}

De voorzitter dankt Van den Muijsenbergh voor zijn voordracht en spreekt haar verwachting uit dat zijn prikkelende betoog de zaal tot reageren zal aanzetten.

Mevrouw Tonkens (oud-rechter, thans mediator, arbiter en bindend adviseur) geeft aan dat bij de totstandkoming van de Verordening is stilgestaan bij de kritiekpunten van Van den Muijsenbergh. De Europese Unie is echter gebaseerd op onderling vertrouwen. Daar hoort een stelsel van reciprociteit bij. In Nederland moeten we niet het werk van de buitenlandse rechter over gaan doen, aldus Tonkens. Zij vraagt zich ook af hoe de Nederlandse rechter met behulp van het openbareordecriterium een grens zou moeten trekken ter voorkoming van misbruik.

Van den Muijsenbergh erkent dat wederzijds vertrouwen een van de pijlers van de Europese Unie is. Daaraan wil hij op zichzelf niets afdoen. Maar de risico's zijn groot. De openbare orde is een vangnet, je kunt daaronder bezwaren van diverse aard vatten. Onderschreven wordt dat het niet gemakkelijk zal zijn om de grens te bepalen. De grens is overschreden als de bevelgevende rechter de schijn van partijdigheid heeft, aldus Van den Muijsenbergh.

Mevrouw Oudshoorn, die aan een proefschrift over het EUbankbeslag werkt, vraagt zich af hoe reëel de mogelijkheid is dat het bevel wordt misbruikt om bankgegevens te verkrijgen. Het bevel moet toch volgens nationaal recht worden geëxecuteerd?

Voor de implementatie wordt volgens Van den Muijsenbergh inderdaad zo veel mogelijk aangesloten bij nationaal recht. Maar dat sluit misbruik niet uit. Het bevel kan zijn verleend door een gecorrumpeerde rechter op basis van een schijnclaim van een non-existente vennootschap.

De heer Hendrikse (advocaat) wil weten welke ruimte de executierechter heeft voor een openbareordetoets.

Schorsing van de executie is mogelijk op basis van de in art. 34 van de Verordening genoemde gronden, aldus Van den Muijsenbergh. En dan zijn er nog de eveneens beperkte gronden van art. 45 van de herschikte EEX-Verordening. Voor een meer omvangrijke toetsing moet de debiteur de procedure van art. 33 van de Verordening volgen en de rechter van het land van uitvaardiging van het bevel verzoeken om dat bevel terug 
te draaien. Dit kan betekenen dat moet worden geprocedeerd in Oost-Europese landen met een traag en niet altijd integer werkend justitieel systeem. Het EU-bankbeslag kan daarom een effectief drukmiddel zijn.

De voorzitter spreekt een kort slotwoord uit, dankt de sprekers en sluit de vergadering. 